\title{
Glia Excitation in the CNS Modulates Intact Behaviors and Sensory-CNS-Motor Circuitry
}

\author{
Shelby McCubbin, Douglas A. Harrison (D) and Robin L. Cooper *(D)
}

Citation: McCubbin, S.; Harrison, D.A.; Cooper, R.L. Glia Excitation in the CNS Modulates Intact Behaviors and Sensory-CNS-Motor Circuitry. Neuroglia 2022, 3, 23-40. https:// doi.org/10.3390/neuroglia3010002

Academic Editor: John T. Weber

Received: 5 December 2021

Accepted: 26 February 2022

Published: 28 February 2022

Publisher's Note: MDPI stays neutral with regard to jurisdictional claims in published maps and institutional affiliations.

Copyright: () 2022 by the authors. Licensee MDPI, Basel, Switzerland. This article is an open access article distributed under the terms and conditions of the Creative Commons Attribution (CC BY) license (https:// creativecommons.org/licenses/by/ $4.0 /)$.

\author{
Department of Biology, University of Kentucky, Lexington, KY 40506-0025, USA; \\ shelby.mcCubbin@uky.edu (S.M.); dough@uky.edu (D.A.H.) \\ * Correspondence: rlcoop1@uky.edu
}

\begin{abstract}
Glial cells play a role in many important processes, though the mechanisms through which they affect neighboring cells are not fully known. Insights may be gained by selectively activating glial cell populations in intact organisms utilizing the activatable channel proteins channel rhodopsin (ChR2XXL) and TRPA1. Here, the impacts of the glial-specific expression of these channels were examined in both larval and adult Drosophila. The Glia > ChR2XXL adults and larvae became immobile when exposed to blue light and TRPA1-expressed Drosophila upon heat exposure. The chloride pump expression in glia $>$ eNpHR animals showed no observable differences in adults or larvae. In the in situ neural circuit activity of larvae in the Glia $>$ ChR2XXL, the evoked activity first became more intense with concurrent light exposure, and then the activity was silenced and slowly picked back up after light was turned off. This decrease in motor nerve activity was also noted in the intact behaviors for Glia > ChR2XXL and Glia > TRPA1 larvae. As a proof of concept, this study demonstrated that activation of the glia can produce excessive neural activity and it appears with increased excitation of the glia and depressed motor neuron activity.
\end{abstract}

Keywords: behavior; channel rhodopsin; circuitry; Drosophila; glia

\section{Introduction}

In general, sensory perception and behavioral responses to sensory stimuli are finely tuned within animals for survival. Neural circuitry is highly specialized and tightly regulated for both an appropriate behavioral response to sensory stimuli and intrinsic control of bodily functions. In disease states, it is noted that an altered perception to a stimulus can be a cue of an underlying neurological issue. Autistic individuals, for example, display altered sensory perception, but the underlying cause is still unknown [1-3]. The normal function of neurons is dependent on supporting cells (glia) and the surrounding ionic environment. Multiple sclerosis (MS) is a prime example of a complex disease manifested by neuronal dysfunction due to inflammation and dysfunctional glial cells, which alter the functionality of neuronal circuitry $[4,5]$.

Understanding the physiological connections and modulation of these connections is a hallmark for therapeutic treatments with pharmacological agents. Besides medications that directly alter neural activity to help manage dysfunction in ion channels and cellular cascades, another approach may be indirect manipulation of the activity of neurons and glia.

There is growing interest in disorders of the glia that affect behavior. The most known glial disease is multiple sclerosis (MS) [6], but it involves more than just the dysfunction of the glia. How the glia can acutely physiologically modify neurons and a local environment has historically been touted in relation to insulating nerves with myelin or myelin-like wrappings (i.e., within invertebrates), $\mathrm{K}^{+}$ion regulation, and recycling of neurotransmitters [7-9]. 
Some of the pioneering research in glia function has come from experimental models using invertebrates [10]. Cell and brain slice cultures allowed for insight into glial physiology within the CNS of mammals [11], and imaging techniques have now advanced to allow for an intact view of cellular interactions in intact mammalian CNS and regulation of glial-lymphatic and glymphatic systems [12,13].

The leech nervous system was one of the first preparations in which physiological measures were obtained in order to demonstrate that the glia membrane potential is related to the activity of the local neurons. The function of the glia was suggested to control the extracellular $\mathrm{K}^{+}$ions when the neurons were electrically active $[10,14,15]$. The glia cells around the optic nerve of the mud puppy (Necturus), an amphibian, behaved similarly to the glia in the leech regarding depolarization when the surrounding neurons were excited [15]. The glia (i.e., Müller cells) within the retina of fish have also been an experimental model for glial function in vertebrates [16].

From these earlier investigations, many studies in mammals and other animals have shown glial cells (i.e., astrocytes, microglia, and oligodendrocytes) also have many other functions in releasing substances (i.e., gliotransmitters and cytokines). They also provide developmental cues to shape the central nervous system $[8,17,18]$, and even the glial Schwann cells at the neuromuscular junction have a role in monitoring neural activity, potentially acting to stabilize the synaptic environment $[7,19]$.

Besides studies on how electrically active neurons influence the glia, it is of interest to learn how electrically active glia impact neurons in a rapid time frame. It is of interest to observe changes in the behavior and nerve activity when the glia are selectively stimulated. This is difficult to accomplish in intact organisms due to the inability to selectively modify the glial membrane potential. However, with the use of genetics using the Drosophila model, light sensitive proteins (i.e., optogenetics) [20-22] and heat sensitive proteins (i.e., TRPA1) can be selectively expressed in the glia to excite the glia while assessing neuronal activity and behavior in both larval and adult Drosophila melanogaster [23]. Optogenetic approaches of activating the glia have been previously used in brain slices of mice [11]. Upon electrically exciting the glia through stimulating the channel rhodopsin with light, the release of glutamate caused neurons to depolarize, which influenced a neural circuit within the brain slice [11]. It is likely that soon, the glia will be selectively excited in intact rodent models with optogenetics to address effects of functional neural circuits such as responses to various forms of sensory input. As a proof of concept, the D. melanogaster can serve as a model for intact studies in the whole animal, as well as in situ, to address the impact of acutely activating the glia and observing the changes in whole animal behavior, as well as alterations in the activity of a functional neural circuit [23]. The types of glial cells in the CNS and segmental nerves of larval D. melanogaster have been described [24-31]. Given that $D$. melanogaster is used as a model for many disease states among mammals, including humans [24,32-34], disease states in the glia function of mammals could also be potentially modeled in D. melanogaster to address the use of optogenetics or other forms of targeting the glia in aiding the reduction of neuronal dysfunction in other animals $[20,34,35]$.

As light can have difficulty in fully penetrating through the cuticle of adult flies and larval tissue in order to alter the glia function, as a proof-of-concept, heat activated channels (TRPA1) can be used to selectively target the glia of both adult and larval Drosophila. Exposing the animal to varying temperatures allows for penetrating throughout these small animals. However, temperature control of the genetically modified expressed channels is not as rapid as light activation and inactivation. For comparisons in controlling the glial activity, both channel rhodopsin and TRPA1 expression were used in this study while examining the effect on the behavior of freely moving animals, as well as examining related nerve activity within in-situ preparations and intact sensory-CNS-motor circuitry.

\section{Methods and Materials}

A number of methodological details have been described in an earlier paper [23] and are highlighted here. 


\subsection{Fly Lines and Optogenetic Procedures}

The same fly lines were used as described in [23], as well as ones to express TRPA1 in the glia. In brief, the flies utilized were obtained from the Bloomington Drosophila Stock Center and were maintained in a laboratory. Flies and larvae were fed a standard cornmealagar-dextrose-yeast medium diet (modified from [36]), were housed at temperatures between 20 and $21{ }^{\circ} \mathrm{C}$, and were maintained on a 12:12 L:D cycle. Animals expressing channel rhodopsin, halorhodopsin, or TRPA1 were generated by crossing virgin females of UAS transgene stocks with males bearing the pan-glial repo-GAL4 driver. Stocks

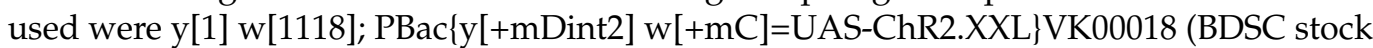
\#58374), $\mathrm{w}^{*}$; P\{UAS-eNpHR-YFP (BDSC\#41752), and UAS-TrpA1 (BDSC stock \#26263) for UAS transgenes and $\mathrm{w}[1118] ; \mathrm{P}\left\{\mathrm{w}\left[+\mathrm{m}^{*}\right]=\mathrm{GAL} 4 \mathrm{repo} / \mathrm{TM} 3\right.$, Sb (BDSC stock \#7415) or alternatively balanced with $\mathrm{TM} 3, \mathrm{P}\{\mathrm{w}[+\mathrm{mC}]=$ ActGFP $\}] M R 2$, Ser derived from BDSC stock \#4534.

A widely used approach in research using Drosophila is the UAS-Gal4 binary expression system, which can be used to target the expression of the effector gene of interest to a subset of cells in a controlled manner [34]. In this study, the channel rhodopsin was expressed in all glia cells. The parental lines (UAS-Chr2XXL) were also examined as controls for the effect of light sensitivity for behaviors and electrophysiological studies. Adults and larvae were screened prior to behaviors and electrophysiology recordings, to ensure we used larvae that were responsive to blue light. The screening entailed a brief $(\sim 5 \mathrm{~s})$ exposure of blue light with a NightSea blue light $(436 \mathrm{~nm}$ ) emitter (NIGHTSEA, 235-Rear Bedford St., Lexington, MA, USA). The control for the halorhodopsin line was the parental line $\mathrm{w}^{*} ; \mathrm{P}\{\mathrm{UAS}-\mathrm{eNpHR}-\mathrm{YFP}\}$ (BDSC\#41752). Using marked balancers expressing either GFP or dominant mutations ( $\mathrm{Sb}$ or $\mathrm{Ser}$ ), it was confirmed that animals responsive to the stimulus carried the repo-GAL4 transgene, while non-responders carried the balancer instead.

The high intensity LEDs used in this study were blue light $(470 \mathrm{~nm}$ wavelength, LED supply, LXML-PB01-0040, $500 \mathrm{~mA}$ ) and yellow-lime light (567.5 $\mathrm{nm}$ wavelength, LED supply, LXML-PM02-0000, $500 \mathrm{~mA}$ ). The $470 \mathrm{~nm}$ blue light was used for the Chr2XXL and $567.5 \mathrm{~nm}$ yellow-lime light was used for the halorhodopsin lines, based on which the wavelengths resulted in maximum activation of the light-sensitive proteins, as determined from the literature $[37,38]$.

The photon flux (number of photons per second per unit area) was measured with a LI-COR (model Li-1000 data Logger, LDL3774; LI-COR from Lincoln, NE, USA) that measured $\mu \mathrm{Mol} \mathrm{s}^{-1} \mathrm{~m}^{-2}$ per $\mu \mathrm{A}$. In addition, the full spectrum of lights was measured with a Jazz (Ocean Optics Inc., Largo, FL, USA) to obtain a total W/m² from 340 to $800 \mathrm{~nm}$ spectrum for each light source.

As described in [23], all trans-Retinal (ATR; Sigma-Aldrich, St. Louis, MO, USA) was diluted in $50 \mathrm{~mL}$ of standard fly food to a final concentration of $200 \mu \mathrm{M}$, and were protected from light with aluminum foil. All trans-Retinal was a cofactor for the channel rhodopsin, which increased its sensitivity to light and increased single channel conductance [20]. ATR (500 mg) was dissolved in $17.6 \mathrm{~mL}$ of absolute ethanol to make $100 \mathrm{mM}$ stock solutions. The stock solution was transferred into small tubes, wrapped with aluminum foil, and kept in a $-20{ }^{\circ} \mathrm{C}$ freezer. The ATR should be kept away from light as it is sensitive to it. The ATR was either mixed well with the fly food or the fly food was dissolved in the microwave. The food was left to cool, then ATR or absolute ethanol was mixed with the food as a control. Both foods were stored in the refrigerator for 3 days, with a cotton plug to allow the $\mathrm{EtOH}$ to evaporate. It had been noted that larval development was slowed in the presence of ethanol, so precautions were taken to limit its developmental influence by evaporating the alcohol [39].

Adults of UAS-ChR2 and Glia > Chr2XXL were fed ATR $24 \mathrm{~h}$ prior to being examined in a vial, and were switched to a vial without food in order to examine their behaviors. Larvae were fed ATR $24 \mathrm{~h}$ prior to the behavioral assays or electrophysiological recordings. Early third instar larvae were used for all electrophysiological studies. 
Screening of the Glia > TRPA1 larva for electrophysiological recordings consisted of a brief exposure to $28^{\circ} \mathrm{C}$ to observe which larvae contracted and stopped moving. The larvae that did not show a response were quickly removed and held in a separate dish with food for later electrophysiological examination. These non-responders as well as UAS-TRPA1 were used as the controls.

\subsection{Intact Adult Behavior}

The assays examined the ability of the ChR2XXL adult to move both during and immediately after either stimulating the glia with TRPA1 or hyperpolarizing the glia with halorhodopsin. The Glia > ChR2XXL and Glia > eNpHR adult flies were anesthetized by exposing them to $\mathrm{CO}_{2}$, and then were placed in plastic vials or petri dishes for the behavioral assays. The testing vial was tapped until all the flies fell into the bottom of the tube. A $10 \mathrm{~s}$ period was set to observe how the flies responded to either the blue or yellow LED lights [40]. Other subsets of the F1 generations were placed into Petri dishes for behavioral analysis in movements in a horizontal plane, which was more convenient for video imaging than the vials.

The righting reflex assay was also a measure of the coordination of the adult flies. After shaking the vials or Petri dishes, it was easy to note the inability of the adults to stand and move. All behavioral assays were repeated and compared to the control flies (parental lines and non-responders).

\subsection{Intact Larval Behavior}

This procedure is described in detail in an earlier report [41], but in brief, individual larvae were placed on an apple juice agar dish to stimulate crawling. Crawling larvae were prodded three times with an insect pin (Fine Science Instruments, $0.2 \mathrm{~mm}$ diameter), once on the tail and once on the side of the abdomen. While watching the larvae through a video camera under IR light, an observer counted the body wall contractions by the number of peristaltic waves for $30 \mathrm{~s}$. These data are reported as the number of body wall contractions per minute. The same behavioral paradigm was used again, but with diffuse blue light over the dish. This was performed for the controls (UAS-ChR2XXL) as well as for the Glia $<$ CHR2XXL animals.

The TRPA1 lines were viewed on the Petri dishes with etched scratches for the larvae to grip for movements. They were placed on the dish before heating. After heating the dish for $3 \mathrm{~min}$ at $28^{\circ} \mathrm{C}$ on a hot plate, the dish was removed from the heat and the larvae were observed over time for regaining crawling function.

\subsection{In Situ Neural Circuit of Larvae}

In order to electrically drive the sensory-CNS-motor circuit and record the effects in a muscle, the larvae were fully fileted. This procedure was detailed earlier [42-44]. In brief, a longitudinal dorsal midline cut was made in the third instar larvae to expose the CNS. The segmental nerves on one side were cut and sucked into a suction electrode, which was filled with saline and stimulated. The segmental nerves were stimulated with trains of stimuli of $40-60 \mathrm{~Hz}$, for 10-15 stimuli within a train. The trains were delivered every 10 s (S88 Stimulator, Astro-Med, Inc., Grass Co., West Warwick, RI, USA). Monitoring the transmembrane potentials of the body wall muscle (m6) was performed as explained above. The blue (Glia > Chr2XXL) or yellow (Glia > eNpHR) light was then either shone on the associated preparations without the electrical stimulation, or concurrently with the electrical stimulation. The same procedure was used for the Glia > TRPA1, but instead of light, the saline bath was exchanged with saline at $25^{\circ} \mathrm{C}$ or $28^{\circ} \mathrm{C}$ while stimulating the sensory segmental nerves on the contralateral side of recording from the muscle fibers. Controls for the effect of temperature were conducted with UAS-TRPA1. 


\subsection{Study Area}

The study was carried out in the Biology Department at the University of Kentucky in Lexington, KY, USA, from August 2021 to February 2022.

\section{Results}

\subsection{Intact Adult Behavior}

Behavioral observations were made using a video camera under IR light, as white light can excite the highly sensitive channel rhodopsin ChR2XXL. As the adults do not move readily in the dark, they need to be lightly shaken or the dish must be tapped with a finger to cause the adults to move. The expression of channel rhodopsin specifically in the glia was accomplished using the GAL4/UAS system [34].

GAL4 expressed under the control of the reversed polarity (repo) gene regulatory elements drives the expression of UAS-ChR in all glia (written here as Glia > ChRXXL). Because the repo-GAL4 insertion must be maintained as a balanced line, about half of the progeny from a cross with UAS-ChRXXL responded to $10 \mathrm{~s}$ of blue light by becoming immobile. The presence of siblings carrying the balancer instead of GAL4 served as a behavioral control. The non-responders were removed, and the responders were allowed $10 \mathrm{~min}$ in the dark before a second exposure of $10 \mathrm{~s}$ of blue light was given to determine the effects of blue light exposure, as seen in Movie S1 (https: / / youtu.be/kW-OBXn8Kcs; accessed on 25 February 2022). As expected, the flies that became immobile after the first blue light exposure behaved the same upon the second exposure. Following sorting based on the behavioral response, examination for dominant markers on the balancer chromosome (Sb, Ser, or GFP) confirmed that non-responders carried the balancer, while responders did not, therefore carried the repo-GAL4 (Movie S1: https:/ /youtu.be/kW-OBXn8Kcs (accessed on 25 February 2022) and Movie S2: https:/ /youtu.be/CKzx3T8BGps (accessed on 25 February 2022) show TM3, Sb and TM3, Ser Act-GFP balancer cross progeny, respectively). The UAS-ChR2XXL parental stock flies were not responsive to the blue light and remained active with the ability to move when the dish was shaken or tapped, although some paused when exposed to the light initially, but quickly regained movement.

To determine the effect of repetitive exposure to blue light, Glia $>$ ChRXXL adults were exposed to $10 \mathrm{~s}$ of blue light and a $3 \mathrm{~min}$ break in IR light until a $10 \mathrm{~s}$ blue light was again shown on the dish. It was clear it took a minute before all of the flies could move around following the shaking of the dish after the first $10 \mathrm{~s}$ of blue light exposure on the dish with the isolated responders. The second $10 \mathrm{~s}$ blue light exposure also paralyzed the adults, but they were able to return to movements within $30 \mathrm{~s}$. After another $3 \mathrm{~min}$ in IR light, a third blue light exposure of $10 \mathrm{~s}$ paralyzed the adults and they were able to start moving sooner than after the second exposure of light.

The glia > eNpHR flies and the control parental line, UAS-eNpHR, showed no observable differences in adults following $10 \mathrm{~s}$ (and even up to $3 \mathrm{~min}$ ) of constant yellow light exposure (data not shown). Thus, the use of this chloride pump expression (glia $>\mathrm{eNpHR}$ ) in the glia cells of the adults to examine behavioral changes was not pursued any further.

As a proof of concept in activating the glia in the intact adults to compare with the activation ChR2XXL in the glia, the TRPA1 expression in the glia and exposure to heat was examined. As with the Glia > ChR2XXL experiment, only half of the progeny carried both GAL4 and UAS transgenes and therefore express TRPA1 in the glia. Glass Petri dishes were used with one dish containing adults of UAS-TRPA1 and another dish containing flies from the repo-GAL4 $x$ UAS-TRPA1 cross. They were moved on to a hot plate at $28{ }^{\circ} \mathrm{C}$ to $29^{\circ} \mathrm{C}$. The flies would move quickly in the dish with UAS-TRPA1 adults, as well as with half the adults in the dish with cross progeny (Movie S3). The other half of the adults in the dish with Glia > TRPA1 fell on their sides and back quickly (Movie S3-https: / / youtu.be/D1QG9Dw2mK0; accessed on 25 February 2022), similar to the way the Glia > ChR2XXL adults reacted following exposure to blue light. As above, examination of the flies from each class revealed that non-responders carried dominant markers from the balancer, and thus lacked repo-GAL4, while the flies that became immo- 
bile did not. As soon as the responders to the heat stopped moving, the dish was taken off of the hot plate. As it took time for the heat to dissipate from the glass dish and the animals, the adults took a longer time to recover and start moving again when compared to the Glia > ChR2XXL flies. However, the rapid paralysis of the Glia > TRPA1 flies to heat indicate that activation of the glia resulted in the animals not being able to move. Furthermore, the legs or wings did not show movement, while the body was initially paralyzed. Upon removal of the heat as the adults were slowly recovering, the adults tried righting themselves and stumbled with some falling back on their side. There was quite a bit of variation in the recovery timing of the adults (Movie S3: https: / youtu.be/D1QG9Dw2mK0; accessed on 25 February 2022), but all Glia > TRPA1 flies were able to eventually recover and move around the dish. In the additional experiments, with small glass Petri dishes and repetition of the same paradigm (with continuous monitoring following the removal of heat), it took approximately $30 \mathrm{~min}$ for the adults to recover despite the dish returning to $22-23{ }^{\circ} \mathrm{C}$ from $28-29^{\circ} \mathrm{C}$ within $5 \mathrm{~min}$. The smaller dishes allowed for zooming in with an enlarged image on all the adults to note the movement of the legs and wings. As with the Glia $>$ ChR2XXL, upon recovering from heat exposure, the legs and wings would move and then stop and then begin moving again, until the adults could right themselves and slowly start walking again.

\subsection{Intact Larval Behavior}

To examine the light sensitivity of the larvae expressing channel rhodopsin or halorhodopsin in the glia, the body wall movements were recorded in IR light, before and during exposure to the associated LED. Crosses were conducted using the repo-GAL4 driver balanced with a GFP-marked chromosome. Ten larvae each from crosses with UAS-ChR2XXL and UAS-eNpHR were monitored (Figure 1). Lack of GFP unambiguously distinguished the larvae expressing the respective channel proteins. Only the Glia > Chr2 XXL animals slowed significantly during the $10 \mathrm{~s}$ of blue light exposure (Movie S4: https:/ /youtu. be/DlbGcWa1Xq0; accessed on 25 February 2022). They then slowly recovered over the next 3 min (Movie S4: https://youtu.be/DlbGcWa1Xq0; accessed on 25 February 2022). The GFP-marked balancer for the Repo-GAL4 line was also readily observed by the GFP marker or the response to blue light (Movie S5-https: / / youtu.be/WcKCB-QFrdQ; accessed on 25 February 2022). The UAS-ChR2XXL parental line showed no change with blue light during or after $10 \mathrm{~s}$ of exposure (Figure 1). The halorhodopsin glial expressers (Glia > eNpHR) and the control for the halorhodopsin (UAS-eNpHR) showed no response to yellow light over $10 \mathrm{~s}$ of exposure, and no response even with a longer continuous $3 \mathrm{~min}$ exposure of yellow light. Thus, the glia $>\mathrm{eNpHR}$ larvae were no longer examined for sensitivity to yellow light.

Body wall movements were monitored for $30 \mathrm{~s}$ and were estimated for movements per minute to compare with the previous literature. There was a significant difference over each time period during the $3 \mathrm{~min}$ for Glia $>$ Chr2XXL compared to the control line (UAS-ChR2XXL) $(n=10, p<0.05$, one way repeated measures analysis of variance, normality test (Shapiro-Wilk), equal variance test (Brown-Forsythe), and all pairwise multiple comparison procedures (Bonferroni $t$-test)). Each minute for the next $2 \mathrm{~min}$, after the blue light was turned off, still showed a reduction in body wall contractions within the group of larvae responsive to blue light $(n=10, p<0.05$, one way repeated measures analysis of variance, normality test (Shapiro-Wilk), equal variance test (Brown-Forsythe), and all pairwise multiple comparison procedures (Bonferroni $t$-test)) (Figure 1).

The effects of activating TRPA1 expressed in the glia of the larvae were examined by placing the larvae in a glass Petri dish and exposing the dish to a hot plate $\left(29^{\circ} \mathrm{C}\right)$. As for the Glia > Chr 2 XXL line, about $50 \%$ of the larvae in the repo-GAL4 $x$ UAS-TRPA1 cross quickly twitched and then elongated, while the others kept wiggling around. The elongated larvae were paralyzed and did not respond to touch (Movie S6: https: / /youtu.be/2uK_zJIKmAY; accessed on 25 February 2022). The genotype of the responders was confirmed to be Glia > TRPA1 through the absence of the GFP-marked balancer). This procedure was used 
to confirm responders and non-responders for later electrophysiological studies. The glass was taken off the hot plate as soon as the larvae elongated and stopped moving. While continuously videoing the dish and observing the larva, it took about $30 \mathrm{~min}$ before the larvae were able to start crawling and responding to prodding again. Thus, the recovery time was similar both for the larvae and adults in activating the TRPA1 in the glia. The non-responders were able to keep moving during the entire length of heat exposure, as well as during the $30 \mathrm{~min}$ of the responders being paralyzed (Movie S6: https:/ /youtu.be/2uK_zJIKmAY; accessed on 25 February 2022).

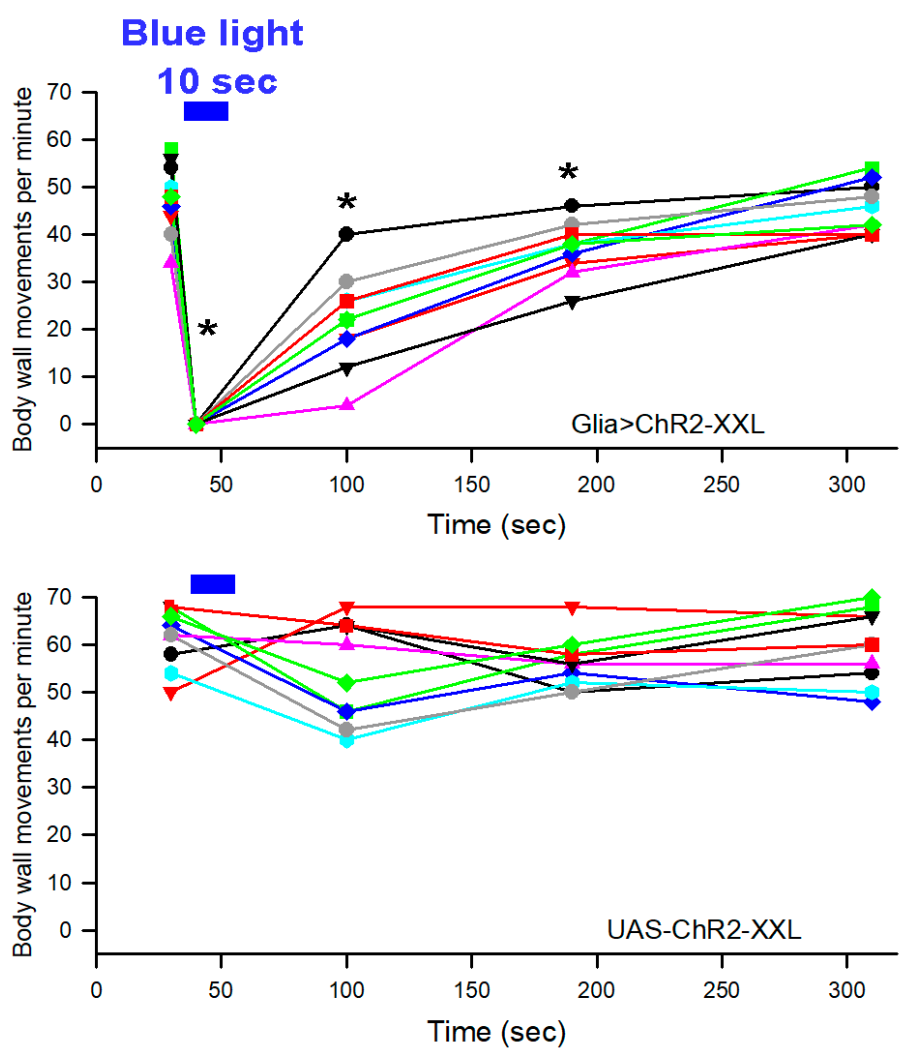

Figure 1. The effect on the larvae body wall movements through the excitation of the glial cells expressing channel rhodopsin (done by shining light on larvae). (A) All 10 larvae of Glia > ChR2XXL stopped moving when the glia cells were activated and then slowly were able to regain movement ability over time with only IR light exposure $\left({ }^{*} n=10, p<0.05\right.$, one way repeated measures analysis of variance, normality test (Shapiro-Wilk), equal variance test (Brown-Forsythe), and all pairwise multiple comparison procedures (Bonferroni $t$-test)). (B) Control larvae treated in the same manner as Glia > ChR2XXL with exposure to ATR for $24 \mathrm{~h}$ and exposed to blue LED light for $10 \mathrm{~s}$. The controls showed no response to light exposure.

\subsection{In Situ Neural Circuit Activity of Larvae}

In order to determine to what degree glial stimulation caused activity of motor neurons and to correlate the observed behaviors to the effects on neural circuitry, the synaptic responses in the muscle fibers was monitored with and without sensory stimulation. White light was required to perform the dissection and placement of the intracellular electrode close to the muscle fiber of the larvae. The white light was kept as dim as possible. After dissection and placement of the preparation on the microscope platform, black felt curtains around the recording set up were closed. After 5 min of dark adapting, the intracellular electrode was carefully moved forward to penetrate the muscle fiber with a hydraulic micromanipulator. When an appropriate resting membrane potential was obtained, electrical stimulation of segmental nerves on the contralateral side was implemented. About $3 / 4$ of all the preparations became damaged and were not able to be 
analyzed due to the muscle contraction, resulting in damage of the fiber by the intracellular electrode. Of the preparations that remained stable, six were able to be recorded for ten trials, in which the first five were controls without light and the next five were with light activation during the stimulation pulse. Representative figures of the responses are shown in Figure 2. The stimulus train induces a series of excitatory junction potentials (EJPs) beyond the time of the stimulus pulses; thus, the circuitry within the CNS is activated to excite the motor neurons and it is not just a 1:1 relationship with the sensory stimulus train (Figure 2B).
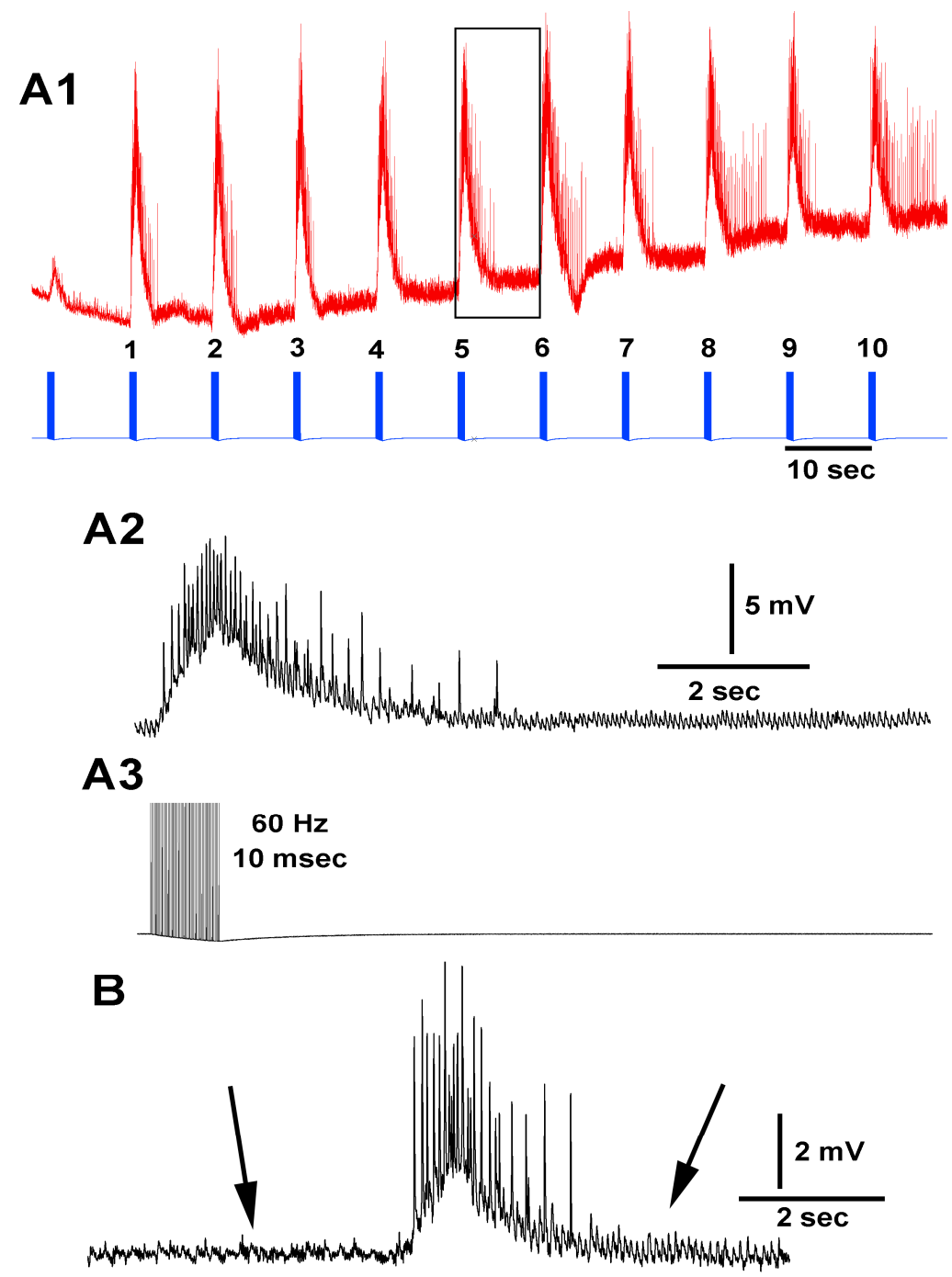

Figure 2. Representative electrically evoked responses in a muscle fiber from a sensory-CNS-motor circuit. (A1) A parental line of Chr2-XXL (control) with electrical stimulation of segmental nerves on the contralateral side from the intracellular recording in the $\mathrm{m} 6$ muscle fiber. The stimulus train ( $60 \mathrm{~Hz}$ for $10 \mathrm{msec}$ ) is delivered 10 times every $10 \mathrm{~s}$. The first stimulus train shown is subthreshold for activating the motor neurons within the neural circuit. The average number of large excitatory junction potentials (EJPs) in the first five trains is compared to the last five trains. (A2) The boxed in area shown in A is enlarged to illustrate the EJPs within $10 \mathrm{~s}$. (A3) The stimulus train is delivered to the segmental nerves to evoke the motor neurons. Note the EJPs continue to occur after the stimulus train is over. (B) When the stimulations are stopped for a minute and one train is delivered, the EJPs resume. Note the small EJPs (second arrow) that occur after the stimulus train for a prolonged time compared to before the stimulation (first arrow). These small EJPs arise due to electronic spread from the $\mathrm{m} 6$ muscle fibers in the adjoining body segments. These small EJPs were not counted in the analysis. 
Electrically driving the sensory-CNS-motor neuron circuit results in the motor nerves being excited when enough stimulation is provided. For Glia $>$ ChR2XXL animals, there is prolonged activation of the induced electrical stimulation when blue light is used in conjunction with electrical stimulation (Figure 3). It is interesting that in four of six preparations, the evoked activity first became more intense with concurrent light exposure and then the activity was silenced and slowly picked back up after the light was turned off and when only electrical stimulation occurred (as shown in Figure 4). In the example shown in Figure 4, the first combined light pulse and electrical stimulation produced a more robust series of evoked EJPs, but by the sixth combined stimuli, the evoked event was depressed. When the light was not combined with the electrical stimulation, the evoked EJPs slowly picked back up.

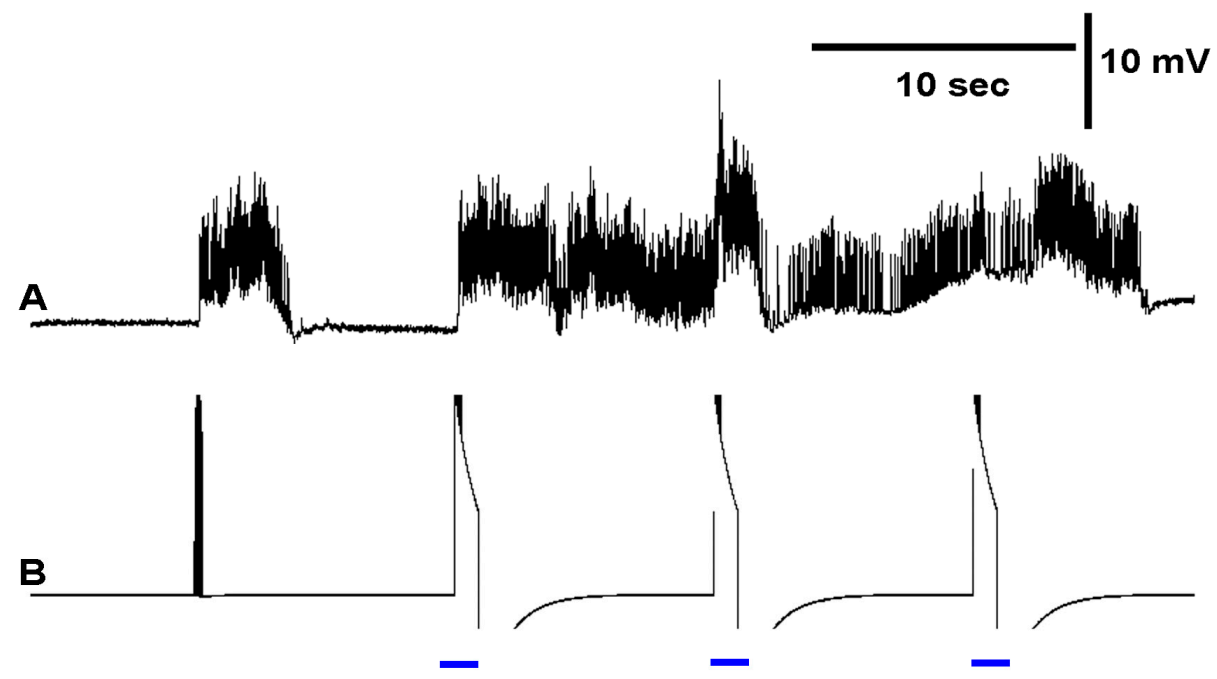

Figure 3. Motor neuron response from sensory stimulation in conjunction with light activation of the glia. (A) EJPs shown with a sensory stimulus train initially, and then followed by sensory stimulation along with blue LED stimulation of ChR2XXL expressed in the glia. (B) Illustration of the sensory stimulus train correlated with EJPs shown in A for the first response and then sensory stimulation along with blue light pulse over the electrical stimulation. The blue light pulses are indicated with dashed lines.

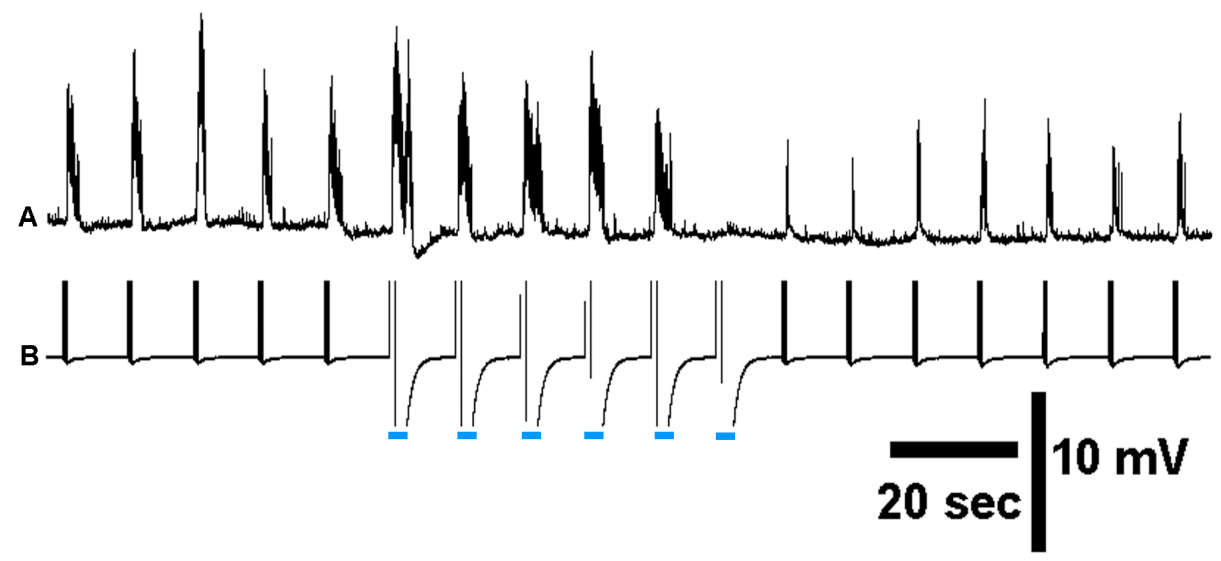

Figure 4. Effect of activating the glia on the electrical stimulation of the sensory nerves, eliciting motor nerve activity to produce EJPs. (A) The EJPs in the muscle are correlated with the electrical stimulation shown in B. Note the evoked EJPs are more robust when light is shone in conjunction with electrical stimulation, but this then depresses the 5th pulse train, and by the 6th light pulse the EJPs are absent altogether. The EJPs slowly come back without the light while continuously providing stimulus trains every $10 \mathrm{~s}$. (B) The stimulus trains and the light pulse along with the electrical stimulation trains are shown by the blue dashes and followed by only the electrical stimulation trains. 
This decrease in motor nerve activity was also noted in the intact behaviors for Glia > ChR2XXL and Glia > TRPA1 when the larvae became flaccid. Thus, it was not practical to quantify counting the number of EJPs as an index, because some evoked sensoryCNS-motor neuron trials are obviously hyperexcited when the glia is activated with light or heat, and as a subsequent trial the electrical drive was abolished with glial activation.

The conditions without light in either the controls, or the UAS-ChR2XXL or Glia > ChR2XXL animals, did not dampen activity. In some cases, with the Glia $>$ ChR2XXL animals, light activation rapidly stopped the sensory drive of activating the motor neurons (Figure 5). The parental control (UAS-ChR2XXL) showed no alteration with exposure to blue light. To illustrate that the GFP-marked balancer for the Repo-GAL4 line and the Repo-Gal4 line were also similar in their responses, trials were also conducted with these lines. The responses were similar, as the ones with a balancer did not respond to blue light, whereas the expressor for ChR2XXL did (Figure 6).

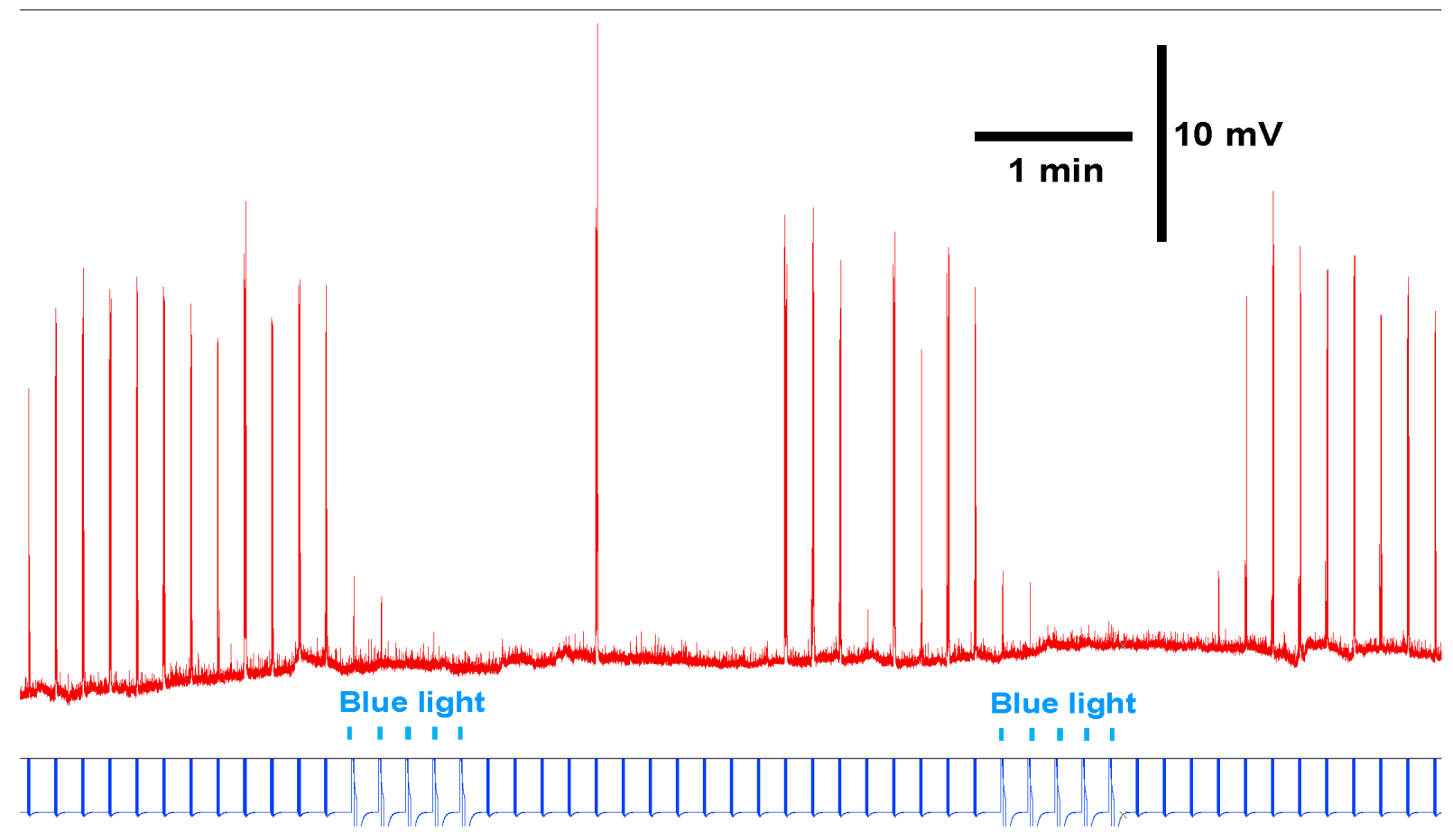

Figure 5. Effect of activating the glia, which rapidly inhibits the responses from the electrical stimulation of the sensory nerves, thus eliciting motor nerve activity to produce EJPs. Note that the evoked responses are rapidly depressed with blue light exposure, and that the depression is repeated after the evoked responses recover.

In examining the Glia > TRPA1 line, when recording the EJPs within the muscle, some bursting was intrinsic, and upon exchanging the saline from $22^{\circ} \mathrm{C}$ to $28^{\circ} \mathrm{C}$, the EJPs became robust and then would dissipate (Figure 7 ). They did not recover over the next $5 \mathrm{~min}$. It appears that activating the TRPA1 in the dissected preparations mimics the intact larval behavior with a prolonged inactivity of the motor neurons.

During earlier experimentation when there was not sufficient recovery time after heat exposure in separating out non-responders and responders of the Glia-GAL4 x UAS-TRPA1 cross, evoked responses could not be induced even with room temperature saline at $21^{\circ} \mathrm{C}$. These larvae were relatively quick to dissect, as they were flaccid and did not resist being pinned to the dissection dish. In hindsight, this was likely still during the long-term recovery of $30 \mathrm{~min}$, as we later learned. So, even with sensory nerve stimulation, the motor nerves were not able to be recruited. Thus, the electrical stimulation while exchanging for warm saline was not pursued further, as maintaining an intracellular recording for $30 \mathrm{~min}$ in the muscle was difficult in these larval preparations after a few recorded contractions. 


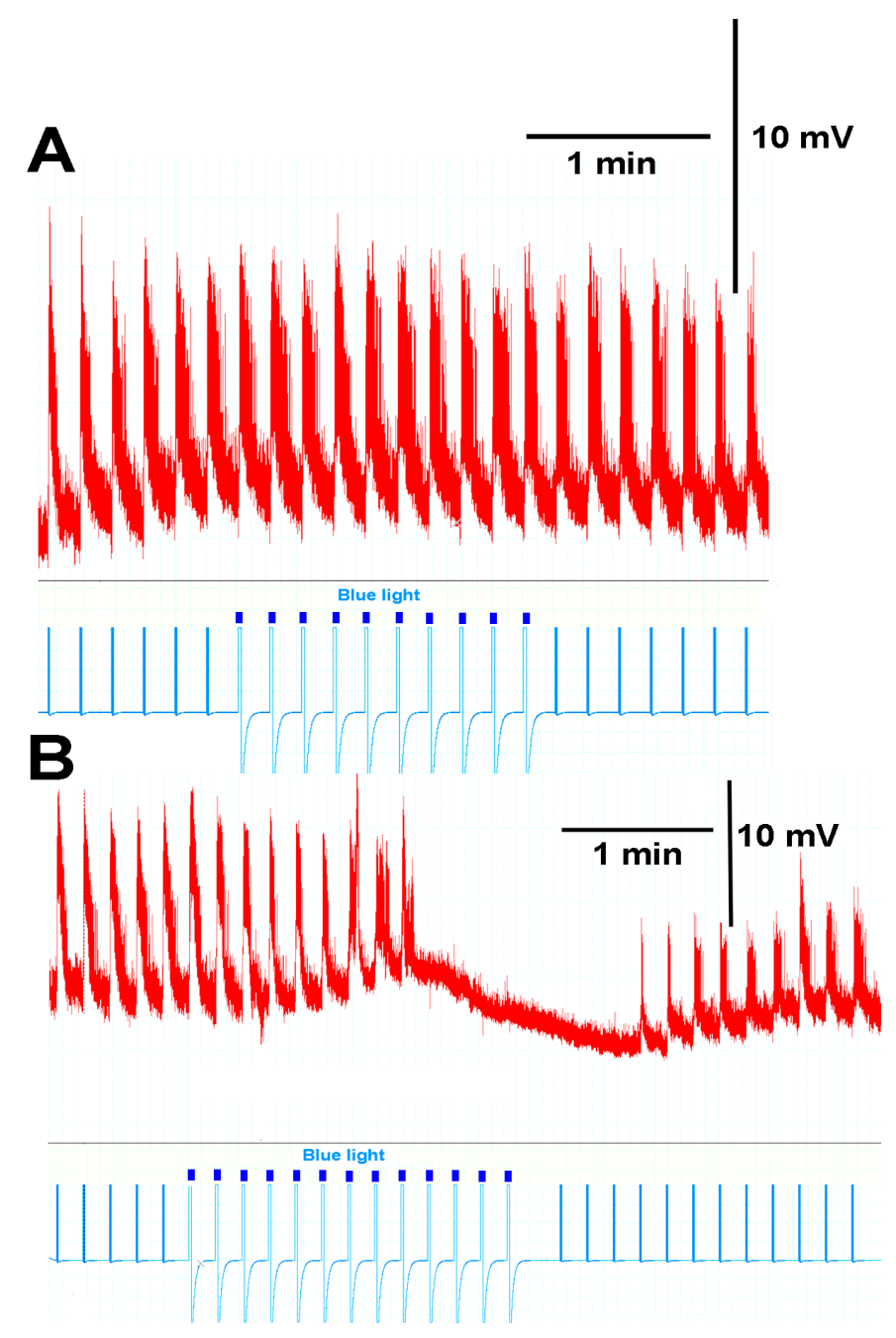

Figure 6. Another line in which the non-expressing ChR2XXL can be identified with a GFP marker and the expressing line of ChR2XXL line does not. (A) The sensory-CNS-motor neural circuit for the GFP-marked balancer for the Repo-GAL4 line was not responsive for the blue light. (B) The Repo-GAL4 line showed an initial increase in response to blue light followed by a period of inhibition of evoked drive of the sensory-CNS-motor neural circuit.

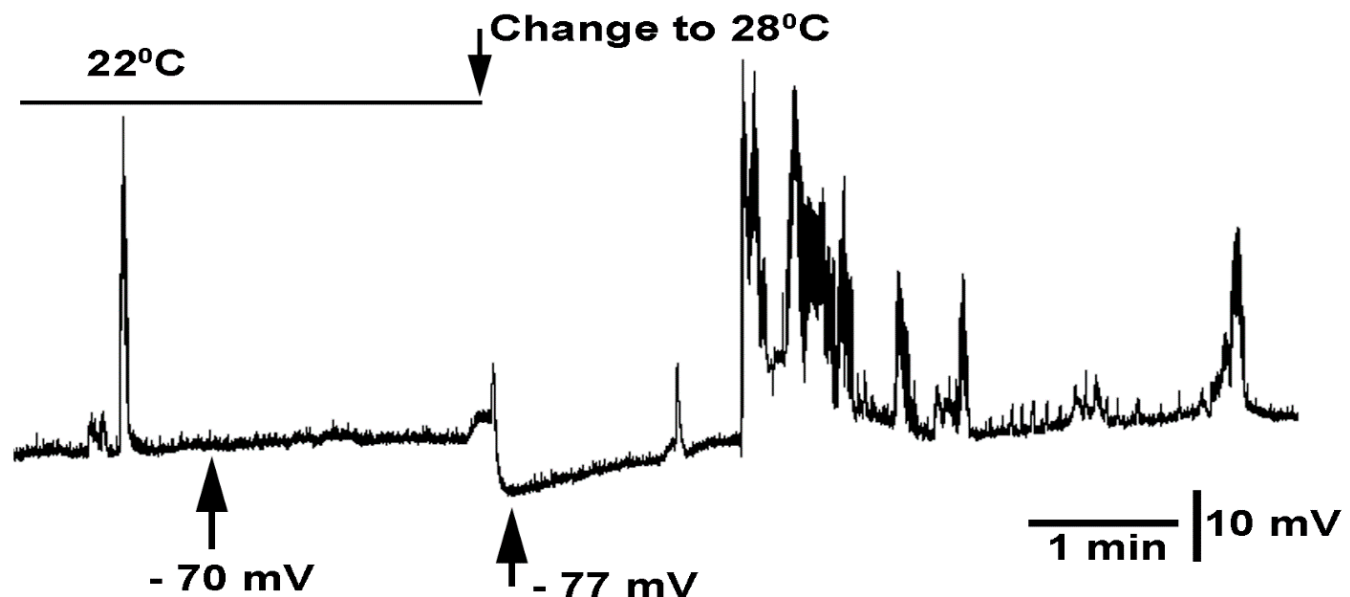

Figure 7. The effect of activating TRPA1 in glial cells on motor nerve activity. There is some spontaneous activity at a constant temperature $22{ }^{\circ} \mathrm{C}$, and upon changing the saline to $28{ }^{\circ} \mathrm{C}$ the resting membrane potential rapidly hyperpolarizes followed by a robust burst and prolonged activity. 


\section{Discussion}

Generally, this study demonstrated in Drosophila adults and larvae that glia activation can initially lead to an increase in body movements and then to paralysis. The recovery from paralysis depends on how the glia are activated, being either through light sensitive channels or temperature sensitive ion channels. The bodily responses are mimicked in the electrophysiological responses from motor neurons, as measured in muscle fibers with intracellular electrodes. Glial excitation stimulates the motor neurons resulting in EJPs in the muscle fibers; however, with increasing the stimulation of the glia, there is a central inhibition of the motor neuron activity relating to the paralysis in the intact larvae and adults.

The conventional view of the glia around the neurons and axons is to buffer the $\mathrm{K}^{+}$, which comes from the neuronal activity. This view comes from the early studies in squid nerves [45], as well as findings that the activity in one axon can influence the electrical activity of another through ephaptic transmission, as noted in the nerves of a crab [46]. This is likely due to the $\mathrm{K}^{+}$build up within the "Frankenhauser space", found between the glia and neurons [45]. Thus, glia dysfunction for being able to maintain the $\mathrm{K}^{+}$balance is likely part of the pathology noted in MS [47]. Besides taking up substances in the near surroundings, the glia is known to release substances that can affect neurons and synaptic communication. Earlier studies in the leech ganglion postulated that the glia may support neurons in metabolic demands as a possible storage source of glycogen [48]. However, it is now established that some forms of glia can be activated to release cytokines, glutamate, and other gliotransmitters [8]. What has not been established until recently [23] is that within intact brains, if the glia are electrically depolarized, there is an impact on the neural function and behavior of the intact animal. Not only is it important to establish whether depolarization has an effect on neurons, but it is important to determine if hyperpolarization also has an effect. Potentially due to the rebound of ionic equilibrium from hyperpolarization, the homeostasis drive by the Na-K ATPase pump in the glia or neurons [49], can lead to hyperexcitability. Alterations in the ionic make-up of cerebral spinal fluid [50,51], as well as the local environment between the glia and neurons, can alter the threshold of neurons. To address this potential of hyperpolarization of the glia having an impact on neuronal function and on the behavior of the animal, an optogenetic approach was taken through the use of a light sensitive $\mathrm{Cl}^{-}$ion pump selectively expressed in the glia of CNS of larva and adult $D$. melanogaster in the study herein. No observable behavioral responses were noted with hyperpolarization of the glia.

The expression of the highly sensitive channel rhodopsin variant ChR2XXL is so sensitive that even dim white light can cause the channel to open. The feeding of adults or larvae ATR produces an even higher sensitivity to light [20]. This increased light sensitivity variant is helpful when examining the adults, as the blue light needs to penetrate through the cuticle and into the CNS to activate the glia. In addition, the efficiency of the expression of the light sensitive proteins in the glial cells of these genetic crosses (i.e., Glia > ChR2XXL) is not yet known.

It is also known that the Drosophila UAS-Gal4 binary expression system is temperature sensitive [51]. As the experiments were conducted in room temperature at 21 to $22{ }^{\circ} \mathrm{C}$, we did not want to introduce another variable by altering the expression with varying temperatures to examine the sensitivity of the Glia $>\mathrm{ChR} 2 \mathrm{XXL}$ animals. This is especially relevant as the temperature sensitive channels were also going to be examined as an additional conformation of the effects of activating glia on the behavior and motor neuron activity with electrophysiology.

It appears there must be a sufficient expression of the ChR2XXL protein when raising the larvae, pupa, and maintaining the adults at room temperature, as the response to light was robust compared to the parental controls (UAS-ChR2XXL), which did not show any noticeable behavioral responses to the LED blue light. Likewise, the larval responses were very notable for the Glia $>$ ChR2XXL compared to the control responses. The sensitivity of stimulating the ChR2XXL without feeding ATR tainted food was not examined as the 
controls and the expressing line were both exposed to ATR, as the goal was to use the most sensitive approaches of stimulating the glia as possible.

The light sensitive channels were better for rapidly turning the response on and off compared to the activation of the glial cells through the temperature sensitive TRPA1 channels. It is hard to know how fast the glia heated up and cooled down, and likely the activation and deactivation were ramping up and down with the temperature. The opening and closing of the channel rhodopsin is very rapid with lights on and off [52]. The TRPA1 channels are rapid as well when examined with cells in culture [52-56]; however, in a whole animal and an intact neural circuit, the temperature changes not only affected the TRPA1 channels, but also the synaptic transmission, ionic pumps, exchangers, and voltage gated channels, not to mention the membrane potential as well as the likely permeability through the voltage gated channels. Thus, the onset and recovery with temperatures were expected to be different than for the light sensitive channels. However, using an additional approach to control the glia activity and observing the resulting behaviors (as well as physiological recordings of the motor nerve responses) provided confidence that both genetic approaches of expressing ChR2XXL or TRPA1, and then activating the glia, gave similar outcomes.

The recovery period following the activation of both larvae and adults expressing ChR2XXL presented with a short time of twitches, uncoordinated movements, and then pauses just prior to fully being able to move again. The adults would right themselves and stand still, but upon shaking the dish, they would sometimes just fall over. This is somewhat reminiscent of the electrical stimulation of the sensory roots, noting a slow recovery in evoking the motor neurons to respond.

It was a bit unexpected that activating the chloride pump with Glia $>$ eNpHR in the adults and larvae did not result in some alterations in behaviors that could readily be noted. If the glia were in fact hyperpolarized, perhaps the effects on the ionic environment around the neurons was not altering the membrane potentials. If genetic lines could be developed where some neurons within the CNS circuitry could be hyperactivated to result in motor neuron firing, and then we were to activate eNpHR in the glia, it is possible that a dampening of hyperactivating a circuit could occur if the hyperpolarization helped to dampen, in some manner, the excess ECF $\mathrm{K}^{+}$concentration. However, presently, it is not known what the effect of hyperpolarizing the glia would be on other glial functions in maintaining the pumps, exchangers, and secretion processes of the glia. If vesicles within the glia were to fuse based on $\mathrm{Ca}^{2+}$ influx and depolarization of the glial membrane, then a hyperpolarization would likely dampen the release of substances from the glia. However, if the glia had receptors for glutamate or other transmitters related to an influx of $\mathrm{Ca}^{2+}$ or $\mathrm{Na}^{+}$ions, then a hyperpolarization would increase the driving gradient of the ions and might lead to a post-hyperpolarization of excitation. If there were voltage gated sodium channels, hyperpolarization could remove basal inactivation, which could transiently lower the threshold for the voltage gated $\mathrm{Na}^{+}$channels post-hyperpolarization, as was noted to occur in the neurons [57].

Repetitive light exposure of Glia > ChR2XXL larvae and adults was shown to be less responsive over time. Even after a period of recovery, where the larval or adults appeared to regain total function, they did not respond as robustly with subsequent $10 \mathrm{~s}$ light pulses. There are various potential reasons to account for the decrease in effect. This behavioral habituation was also noted in the electrophysiological responses. However, if the electrophysiological measures were not performed, one would assume there was just a lack of sensory dive to the neural circuit. With electrical stimulation of the in-situ preparation, the ability to activate the motor neurons could go on for minutes with repeated electrical stimulation of the sensory input. However, if the glia were activated with heat for a prolonged time with Glia > TRPA1, the larvae did not respond to physical prodding. As the position of the larvae and adults of Glia > TRPA1 appeared in a flaccid state when overactivated, it is likely that the neural circuit was fully blocked. Glia > ChR2XXL habituation was not observed with one $10 \mathrm{~s}$ stimulation. However, with multiple $10 \mathrm{~s}$ stimulations with $3 \mathrm{~min}$ in IR only light in-between blue light exposures, the subsequent responses to light 
exposure were not as effective at producing a prolonged contraction state; thus, speeding up recovery time for the larvae. It was hard to observe an enhanced motor nerve activation in the adults as a contracted state as with larvae was not readily observed. However, the adults did not stay paralyzed for as long with repetitive light exposure. The larvae also did not stay in a state of contraction for as long, and may even have shown some very slow movements after several repetitive light exposures. For the ChR2XXL protein in association with ATR, it was possible that ATR was desensitized to the light and therefore had less of an effect at enhancing the ChR2XXL channel to respond to light. The ChR2XXL protein itself also showed desensitization to light, even within a single short light pulse [20]. The possibility of light induced inactivation of the ChR2XXL channel or the question of whether a refractory period was required for the ChR2XXL to regain function in the glia cells studied in this report were not addressed.

It is of interest to understand the mechanisms behind the initial enhanced activity of the neural circuitry followed with neural depression by light stimulation itself or even in conjunction with the sensory drive. The possibility of the motor neurons being excited by the release of gliotransmitters or $\mathrm{K}^{+}$ions from the depolarized glia could account for the burst of activity, and this could be altered over time with more release of glutamate or $\mathrm{K}^{+}$ions induced, such that the receptors to glutamate were desensitized and/or that the heightened $\mathrm{K}^{+}$concentration excited the motor neurons, followed by depolarization inactivation of the voltage gated sodium channels. The recovery period for the motor neurons to regain sensitivity to even the sensory drive or an internal drive could take time to dampen the concentration of gliotransmitters or $\mathrm{K}^{+}$ions in the tight spaces between the glia and neurons.

There could very well be a glial syncytium, which would then interact with a variety of neurons all at once. So, sensory input could activate a glial syncytium that could influence sensory, interneurons, and motor neurons differently. Just as likely, selective glial activation could have the same effect on glial syncytium and thus on multiple types of neurons. Such an activation of the glial syncytium in the CNS of rodents has been discussed [58].

If the glia in the CNS of Drosophila has a syncytium, then the movement of $\mathrm{K}^{+}$ions from local regions with a neural activity could be moved through gap junctions to other glial cells to help in buffering the $\mathrm{K}^{+}$load, as proposed in mammalian systems [58]. In addition, $\mathrm{Ca}^{2+}$ loading in the glia is likely as important, as gap junctions are known to show sensitivity in the cytoplasmic levels of $\mathrm{Ca}^{2+}$ and protons $[59,60]$. The idea of balancing the ionic movement of ions $\left(\mathrm{Ca}^{2+}\right)$ and protons $\left(\mathrm{H}^{+}\right)$is important for balancing the bioelectromagnetic fields in a tight compartment such as the CNS of any animal [58]. If it were possible in these small brains of the larvae or adult Drosophila to electrophysiological explore a possible syncytial isopotentiality when activating one region and recording in another, as possible in mammals [61], then this could be directly addressed. It is known in crayfish, from anatomical and dye studies, there is some sort of syncytium among the glia in the ventral nerve cord. These structures are referred to as "trans-glial channels" [62].

With the advent of imaging and $\mathrm{pH}$ sensitive indicators and maybe voltage sensitive dyes, it would be possible to drive a sensory input and see the spread of the depolarization throughout the CNS, and if the glia are also impacted equally though a syncytium. This has yet been attempted in the Drosphila model. As, indeed, $\mathrm{Ca}^{2+}$ has a role in the communication among astrocytes, even in their ephaptic coupling with neurons, there are many avenues to address. As, in Drosophila, one is able to express $\mathrm{Ca}^{2+}$ indicators in cells and the glia, then one can examine if neural activity within the CNS of larvae and adults produces $\mathrm{Ca}^{2+}$ signals in the glia. It was recently shown that there is a $\mathrm{Ca}^{2+}$ wave in the glia within the segmental roots of larval Drosophila [63]. This recently reported finding is exciting, as this provides a key to the possibility of influencing neural activity along the axon based on the nerve activity itself or from other neurons within the same segmental nerve. This would have an influence of afferent sensory and efferent motor activity. There are many additional experimental paradigms to conduct in order to better understand the interactions of the glia and neural networks, as well as within peripherial nerves. 
Pharmacological approaches to target the Na-K ATPase pump in the glia or the glutamate receptors on the motor neurons would have broad effects on both the glia and neurons, making it still difficult to determine the mechanism in the biphasic effect on the motor neurons from glia activation. In earlier studies, when motor neurons were selectively excited through the use of ChR2XXL, they also showed this biphasic effect of excitation and then depression for some time [24]. However, in these earlier studies, it was known that the motor neurons were directly stimulated and there was an influx of $\mathrm{Ca}^{2+}$ and $\mathrm{Na}^{+}$ through the ChR2XXL channels. Through the genetic expression of $\mathrm{Ca}^{2+}$ indicators in motor neurons along with ChR2XXL in the glia, the mechanisms of excitation and then depression can potentially be addressed for the motor neurons. It remains to be determined whether the activation of the glia is direct on motor neuron excitability or sensory endings or interneurons, or even a combination of effects of the circuit as a whole.

Long term perturbation of glia excitation, such as once every few hours over development, could manifest into more chronic effects, even in the absence of glia activation. Addressing this effect over development with the fruit fly model is possible. However, as with chronic disease states, such as MS in animals, it is not just the glia that are impacted, but rather a combination of factors. Glial dysfunction is only part of the issue in MS, as the channels in the neurons start to change in distribution and density as demyelination occurs, as well as the general inflammation itself changes with activated microglia exposure of cytokines from immune cell invasion, all of which can alter neural function. Such complications can occur within the Drosophila model system, as well if the glia are damaged by the repetitive stimulation or if compensatory mechanisms in the neurons take place. It would be of interest to know if such developmental alterations do take place with this relatively easy model in order to map the changes in the neural circuitry, as well as behavioral responses such as crawling, righting reflex, and flying, and even associative learning in regard to larval and adult Drosophila $[64,65]$.

As a proof of concept, this study has demonstrated that activation of the glia can produce excessive neural activity, and this appears with increased excitation of the glia as well as depressed motor neuron activity. However, the cause of this is unknown, regarding whether the glial excitation is activating an inhibitory input on motor neurons or if the glial activity is directly inhibiting the motoneurons though ionic imbalance in the ECF. The direct inhibition could potentially be due to $\mathrm{K}^{+}$being expelled from the glia, producing an increased activity and then depolarizing the motor neurons and not allowing the motor neurons to repolarize to remove voltage-gated sodium channel inactivation due to depolarization. Hopefully, this study will initiate future studies regarding the mechanisms behind these behavioral observations and measures on nerve activity.

Supplementary Materials: The following supporting information can be downloaded at: https: //www.mdpi.com/article/10.3390/neuroglia3010002/s1. Movie S1: The F1 generation of y[1] $\mathrm{w}$ [1118]; PBac\{y[+mDint2] $\mathrm{w}[+\mathrm{mC}]=\mathrm{UAS}-\mathrm{ChR2.XXL \} VK00018} \mathrm{and} \mathrm{the} \mathrm{pan-glial} \mathrm{driver} \mathrm{w}[1118]$; $\left.\mathrm{P}\left\{\mathrm{w}\left[+\mathrm{m}^{*}\right]=\mathrm{GAL}\right\}\right\} \mathrm{repo} / \mathrm{TM} 3, \mathrm{Sb}$ produced Glia $>$ ChR2XXL. Movie S2: The F1 generation using the GFP-marked balancer line TM3, $\mathrm{P}\{\mathrm{w}[+\mathrm{mC}]=A c t G F P\} J M R 2$, Ser was not sensitive to blue light, whereas the non- GFP animals were paralyzed upon exposure to blue light due to ChR2XXL being expressed in the glia (Glia $>$ ChR2XXL). Movie S3: The F1 generation of UAS-TRPA1 was crossed with the pan-glial driver $\mathrm{w}[1118] ; \mathrm{P}\left\{\mathrm{w}\left[+\mathrm{m}^{*}\right]=\mathrm{GAL} 4\right\} \mathrm{repo} / \mathrm{TM} 3, \mathrm{Sb}$ producing the Glia $>\mathrm{TRPA} 1$ line. Movie S4: Larvae expressing channel rhodopsin in the Glia > Chr2 XXL line when exposed to blue LED light for $10 \mathrm{~s}$ were paralyzed. Movie S5: Larvae in F1 generation using the GFP-marked balancer line TM3, $\mathrm{P}\{\mathrm{w}[+\mathrm{mC}]=\mathrm{Act} G F P\} J M R 2$. Movie S6: Larvae expressing the temperature sensitive TRPA1 channel in the Glia > TRPA1 line and the parental line UAS-TRPA1 were exposed to heat.

Author Contributions: Conceptualization, S.M., D.A.H. and R.L.C.; methodology, S.M., D.A.H. and R.L.C.; software, S.M., D.A.H. and R.L.C.; validation, S.M., D.A.H. and R.L.C.; formal analysis, S.M., D.A.H. and R.L.C.; investigation, S.M., D.A.H. and R.L.C.; resources, S.M., D.A.H. and R.L.C.; data curation, R.L.C.; writing —original draft preparation, S.M., D.A.H. and R.L.C.; writing—review and editing, S.M., D.A.H. and R.L.C.; visualization, S.M., D.A.H. and R.L.C.; supervision, S.M., D.A.H. 
and R.L.C.; project administration, S.M., D.A.H. and R.L.C.; funding acquisition, S.M., D.A.H. and R.L.C. All authors have read and agreed to the published version of the manuscript.

Funding: Funding provided by University of Kentucky Neuroscience Research Priority Area to S.M. and Chellgren Endowed Funding to R.L.C. Stocks obtained from the Bloomington Drosophila Stock Center (NIH P40OD018537) were used in this study.

Institutional Review Board Statement: Not applicable.

Informed Consent Statement: Not applicable.

Data Availability Statement: All data are available in the manuscript and are available upon request.

Conflicts of Interest: The authors declare no conflict of interest.

\section{References}

1. El-Ansary, A.; Hassan, W.M.; Qasem, H.; Das, U.N. Identification of biomarkers of impaired sensory profiles among autistic patients. PLoS ONE 2016, 11, e0164153. [CrossRef] [PubMed]

2. Zhou, H.Y.; Yang, H.X.; Cui, X.L.; Shi, L.J.; Gong, J.B.; Lui, S.S.Y.; Cheung, E.F.C.; Watanabe, K.; Chan, R.C.K. Self-reported sensory responsiveness patterns in typically-developing and early-onset schizophrenia adolescents: Its relationship with schizotypal and autistic traits. J. Psychiatr. Res. 2020, 131, 255-262. [CrossRef] [PubMed]

3. Zhou, H.Y.; Yang, H.X.; Shi, L.J.; Lui, S.S.Y.; Cheung, E.F.C.; Chan, R.C.K. Correlations between audiovisual temporal processing and sensory responsiveness in adolescents with autistic traits. J. Autism Dev. Disord. 2021, 51, 2450-2460. [CrossRef]

4. $\quad$ Filippi, M.; Preziosa, P.; Langdon, D.; Lassmann, H.; Paul, F.; Rovira, À.; Schoonheim, M.M.; Solari, A.; Stankoff, B.; Rocca, M.A. Identifying progression in multiple sclerosis: New perspectives. Ann. Neurol. 2020, 88, 438-452. [CrossRef] [PubMed]

5. Rus, H.; Pardo, C.A.; Hu, L.; Darrah, E.; Cudrici, C.; Niculescu, T.; Niculescu, F.; Mullen, K.M.; Allie, R.; Guo, L.; et al. The voltage-gated potassium channel Kv1.3 is highly expressed on inflammatory infiltrates in multiple sclerosis brain. Proc. Natl. Acad. Sci. USA 2005, 102, 11094-11099. [CrossRef] [PubMed]

6. Coggan, J.S.; Bittner, S.; Stiefel, K.M.; Meuth, S.G.; Prescott, S.A. Physiological dynamics in demyelinating diseases: Unraveling complex relationships through computer modeling. Intl. J. Mol. Sci. 2015, 16, 21215-21236. [CrossRef] [PubMed]

7. Auld, D.S.; Robitaille, R. Glial cells and neurotransmission: An inclusive view of synaptic function. Neuron 2003, 40, 389-400. [CrossRef]

8. Sancho, L.; Contreras, M.; Allen, N.J. Glia as sculptors of synaptic plasticity. Neurosci. Res. 2021, 167, 17-29. [CrossRef]

9. Einheber, S.; Bhat, M.; Salzer, J. Disrupted axo-glial junctions result in accumulation of abnormal mitochondria at nodes of Ranvier. Neuron Glia Biol. 2006, 2, 165-174. [CrossRef]

10. Kuffler, S.W.; Potter, D.D. Glia in the leech central nervous system: Physiological properties and neuron-glia relationship. J. Neurophysiol. 1964, 27, 290-320. [CrossRef]

11. Sasaki, T.; Beppu, K.; Tanaka, K.F.; Fukazawa, Y.; Shigemoto, R.; Matsui, K. Application of an optogenetic byway for perturbing neuronal activity via glial photostimulation. Proc. Natl. Acad. Sci. USA 2012, 109, 20720-20725. [CrossRef] [PubMed]

12. Rennels, M.L.; Gregory, T.F.; Blaumanis, O.R.; Fujimoto, K.; Grady, P.A. Evidence for a 'paravascular' fluid circulation in the mammalian central nervous system, provided by the rapid distribution of tracer protein throughout the brain from the subarachnoid space. Brain Res. 1985, 326, 47-63. [CrossRef]

13. Jessen, N.A.; Munk, A.S.; Lundgaard, I.; Nedergaard, M. The Glymphatic System: A Beginner's Guide. Neurochem. Res. 2015, 40, 2583-2599. [CrossRef] [PubMed]

14. Baylor, D.A.; Nicholls, J.G. Changes in extracellular potassium concentration produced by neuronal activity in the central nervous system of the leech. J. Physiol. 1969, 203, 555-569. [CrossRef] [PubMed]

15. Kuffler, S.W.; Nicholls, J.G.; Orkand, R.K. Physiological properties of glial cells in the central nervous system of amphibia. J. Neurophysiol. 1966, 29, 768-787. [CrossRef] [PubMed]

16. Mitarai, G.; Svaetichin, G.; Vallecalle, E.; Fatechand, R.; Villegas, J.; Laufer, M. Glia-neuron interactions and adaptational mechanisms of the retina. In The Visual System; Jung, R., Kornhuber, H., Eds.; Springer: Berlin/Heidelberg, Germany, 1961.

17. Robitaille, R. Purinergic receptors and their activation by endogenous purines at perisynaptic glial cells of the frog neuromuscular junction. J. Neurosci. 1995, 15, 7121-7131. [CrossRef]

18. Todd, K.J.; Robitaille, R. Purinergic modulation of synaptic signalling at the neuromuscular junction. Pflugers Arch. 2006, 452, 608-614. [CrossRef]

19. Barik, A.; Li, L.; Sathyamurthy, A.; Xiong, W.C.; Mei, L. Schwann cells in neuromuscular junction formation and maintenance. J. Neurosci. 2016, 36, 9770-9781. [CrossRef]

20. Dawydow, A.; Gueta, R.; Ljaschenko, D.; Ullrich, S.; Hermann, M.; Ehmann, N.; Gao, S.; Fiala, A.; Langenhan, T.; Nagel, G.; et al. Channelrhodopsin-2-XXL, a powerful optogenetic tool for low-light applications. Proc. Natl. Acad. Sci. USA 2014, 111, 13972-13977. [CrossRef]

21. Deisseroth, K. Optogenetics: 10 years of microbial opsins in neuroscience. Nat. Neurosci. 2015, 18, 1213-1225. [CrossRef] 
22. Han, X.; Boyden, E.S. Multiple-color optical activation, silencing, and desynchronization of neural activity, with single-spike temporal resolution. PLoS ONE 2007, 2, e299. [CrossRef] [PubMed]

23. Pankau, C.; McCubbin, S.; Cooper, R.L. The effect of optogenetically activating glia on neuronal function. Neuroglia 2021, 2, 57-67. [CrossRef]

24. Kim, T.; Song, B.; Lee, I.S. Drosophila Glia: Models for Human Neurodevelopmental and Neurodegenerative Disorders. Int. J. Mol. Sci. 2020, 21, 4859. [CrossRef] [PubMed]

25. Stork, T.; Engelen, D.; Krudewig, A.; Silies, M.; Bainton, R.J.; Klämbt, C. Organization and function of the blood-brain barrier in Drosophila. J. Neurosci. 2008, 28, 587-597. [CrossRef] [PubMed]

26. MacNamee, S.E.; Liu, K.E.; Gerhard, S.; Tran, C.T.; Fetter, R.D.; Cardona, A.; Tolbert, L.P.; Oland, L.A. Astrocytic glutamate transport regulates a Drosophila CNS synapse that lacks astrocyte ensheathment. J. Comp. Neurol. 2016, 524, 1979-1998. [CrossRef] [PubMed]

27. Ito, K.; Urban, J.; Technau, G.M. Distribution, classification, and development of Drosophila glial cells in the late embryonic and early larval ventral nerve cord. Rouxs Arch. Dev. Biol. 1995, 204, 284-307. [CrossRef]

28. Beckervordersandforth, R.M.; Rickert, C.; Altenhein, B.; Technau, G.M. Postembryonic development of the midline glia in the CNS of Drosophila: Proliferation, programmed cell death, and endocrine regulation. Mech. Dev. 2008, 125, 542-557. [CrossRef]

29. Awasaki, T.; Lai, S.-L.; Ito, K.; Lee, T. Organization and postembryonic development of glial cells in the adult central brain of Drosophila. J. Neurosci. 2008, 28, 13742-13753. [CrossRef]

30. Muthukumar, A.K.; Stork, T.; Freeman, M.R. Activity-dependent regulation of astrocyte GAT levels during synaptogenesis. Nat. Neurosci. 2014, 17, 1340-1350. [CrossRef]

31. Peco, E.; Davla, S.; Camp, D.; Stacey, S.M.; Landgraf, M.; van Meyel, D.J. Drosophila astrocytes cover specific territories of the CNS neuropil and are instructed to differentiate by Prospero, a key effector of Notch. Development 2016, 143, 1170-1181. [CrossRef]

32. Higgins, J.; Hermanns, C.; Malloy, C.; Cooper, R.L. Considerations in repetitive activation of light sensitive ion channels for long term studies: Channel rhodopsin in the Drosophila model. Neurosci. Res. 2017, 125, 1-10. [CrossRef] [PubMed]

33. Akasaka, T.; Ocorr, K. Drug discovery through functional screening in the Drosophila heart. Methods Mol. Biol. 2009, 577, 235-249. [CrossRef] [PubMed]

34. Brand, A.H.; Perrimon, N. Targeted gene expression as a means of altering cell fates and generating dominant phenotypes. Development 1993, 118, 401-415. [CrossRef] [PubMed]

35. Bellen, H.J.; Tong, C.; Tsuda, H. 100 years of Drosophila research and its impact on vertebrate neuroscience: A history lesson for the future. Nat. Rev. Neurosci. 2010, 11, 514-522. [CrossRef]

36. Pandey, U.B.; Nichols, C.D. Human disease models in Drosophila melanogaster and the role of the fly in therapeutic drug discovery. Pharmacol. Rev. 2011, 63, 411-436. [CrossRef]

37. Lewis, E.B. A new standard food medium. Drosoph. Inf. Ser. 1960, 34, 117-118.

38. Zhao, S.; Cunha, C.; Zhang, F.; Liu, Q.; Gloss, B.; Deisseroth, K.; Augustine, G.J.; Feng, G. Improved expression of halorhodopsin for light-induced silencing of neuronal activity. Brain Cell Biol. 2008, 36, 141-154. [CrossRef]

39. Govorunova, E.G.; Sineshchekov, O.A.; Janz, R.; Liu, X.; Spudich, J.L. Natural light-gated anion channels: A family of microbial rhodopsins for advanced optogenetics. Science 2015, 349, 647-650. [CrossRef]

40. Potter, S.; Sifers, J.; Yocom, E.; Blümich, S.L.E.; Potter, R.; Nadolski, J.; Harrison, D.A.; Cooper, R.L. Acute and chronic effects of inhibiting dTOR by rapamycin on development, behavior, and physiology in Drosophila. Biol. Open 2019, 8, bio046508. [CrossRef]

41. Majeed, Z.R.; Abdeljaber, E.; Soveland, R.; Cornwell, K.; Bankemper, A.; Koch, F.; Cooper, R.L. Modulatory action by the serotonergic system: Behavior and neurophysiology in Drosophila melanogaster. Neural Plast. 2016, 2016, 7291438. [CrossRef]

42. Titlow, J.S.; Rice, J.; Majeed, Z.R.; Holsopple, E.; Biecker, S.; Cooper, R.L. Anatomical and genotype-specific mechanosensory responses in Drosophila melanogaster larvae. Neurosci. Res. 2014, 83, 54-63. [CrossRef] [PubMed]

43. Dasari, S.; Cooper, R.L. Modulation of sensory to motor circuits by serotonin, octopamine, and dopamine in semi-intact Drosophila larva. Neurosci. Res. 2004, 48, 221-227. [CrossRef] [PubMed]

44. Malloy, C.; Somasundaram, E.; Omar, A.; Bhutto, U.; Medley, M.; Dzubuk, N.; Cooper, R.L. Pharmacological identification of cholinergic receptor subtypes: Modulation of locomotion and neural circuit excitability in Drosophila larvae. Neurosci. IBRO 2019, 411, 47-64. [CrossRef] [PubMed]

45. Frankenhauser, B.; Hodgkin, A.L. The after-effects of impulses in the giant nerve fibers of Loligo. J. Physiol. 1956, 131, 341-376. [CrossRef]

46. Katz, B.; Schmitt, O.H. Electric interaction between two adjacent nerve fibres. J Physiol. 1940, 97, 471-488. [CrossRef]

47. Freiha, J.; Riachi, N.; Chalah, M.A.; Zoghaib, R.; Ayache, S.S.; Ahdab, R. Paroxysmal symptoms in multiple sclerosis-A review of the literature. J. Clin. Med. 2020, 9, 3100. [CrossRef]

48. Friede, R. Der Kohlenhydratgehalt der Glia von Hirudo bei verschiedenen Funktionszustanden. Z. Zellforsch. 1954, 41, 509-520. [CrossRef]

49. Angstadt, J.D.; Friesen, W.O. Modulation of swimming behavior in the medicinal leech. II. Ionic conductances underlying serotonergic modulation of swim-gating cell 204. J. Comp. Physiol. A 1993, 172, 235-248. [CrossRef]

50. Akaishi, T.; Takahashi, T.; Himori, N.; Takeshita, T.; Nakazawa, T.; Aoki, M.; Nakashima, I. Chloride imbalance is involved in the pathogenesis of optic neuritis in neuromyelitis optica. J. Neuroimmunol. 2018, 320, 98-100. [CrossRef] 
51. Bondoli, A.; Magalini, S.I.; de Angelis, C.; Foti, A.; Rodolà, F.; Mascaro, A.; Ranieri, R. Changes in plasma and cerebrospinal fluid electrolytes in hypercapnia. Resuscitation 1981, 9, 99-102. [CrossRef]

52. Honjo, K.; Hwang, R.Y.; Tracey, W.D., Jr. Optogenetic manipulation of neural circuits and behavior in Drosophila larvae. Nat. Protoc. 2012, 7, 1470-1478. [CrossRef] [PubMed]

53. Paulsen, C.E.; Armache, J.-P.; Gao, Y.; Cheng, Y.; Julius, D. Structure of the TRPA1 ion channel suggests regulatory mechanisms. Nat. Cell Biol. 2015, 520, 511-517. [CrossRef]

54. Wang, H.; Schupp, M.; Zurborg, S.; Heppenstall, P.A. Residues in the pore region of Drosophila transient receptor potential A1 dictate sensitivity to thermal stimuli. J. Physiol. 2013, 591, 185-201. [CrossRef] [PubMed]

55. Hamada, F.N.; Rosenzweig, M.; Kang, K.; Pulver, S.R.; Ghezzi, A.; Jegla, T.J.; Garrity, P.A. An internal thermal sensor controlling temperature preference in Drosophila. Nat. Cell Biol. 2008, 454, 217-220. [CrossRef] [PubMed]

56. Cao, D.-S.; Zhong, L.; Hsieh, T.-H.; Abooj, M.; Bishnoi, M.; Hughes, L.; Premkumar, L.S. Expression of Transient Receptor Potential Ankyrin 1 (TRPA1) and Its Role in Insulin Release from Rat Pancreatic Beta Cells. PLoS ONE 2012, 7, e38005. [CrossRef] [PubMed]

57. Nadim, F.; Olsen, O.H.; De Schutter, E.; Calabrese, R.L. Modeling the leech heartbeat elemental oscillator. I. Interactions of intrinsic and synaptic currents. J. Comput. Neurosci. 1995, 3, 215-235. [CrossRef] [PubMed]

58. Martinez-Banaclocha, M. Astroglial isopotentiality and calcium-associated biomagnetic field effects on cortical neuronal coupling. Cells 2020, 9, 439. [CrossRef]

59. Peracchia, C. Increase in gap junction resistance with acidification in crayfish septate axons is closely related to changes in intracellular calcium but not hydrogen ion concentration. J. Membr. Biol. 1990, 113, 75-92. [CrossRef]

60. Malchow, R.P.; Tchernookova, B.K.; Choi, J.V.; Smith, P.J.S.; Kramer, R.H.; Kreitzer, M.A. Review and hypothesis: A potential common link between glial cells, calcium changes, modulation of synaptic transmission, spreading depression, migraine, and epilepsy-H. Front. Cell Neurosci. 2021, 15, 693095. [CrossRef]

61. Kiyoshi, C.M.; Du, Y.; Zhong, S.; Wang, W.; Taylor, A.T.; Xiong, B.; Ma, B.; Terman, D.; Zhou, M. Syncytial isopotentiality: A system-wide electrical feature of astrocytic networks in the brain. Glia 2018, 66, 2756-2769. [CrossRef]

62. Shivers, R.R.; Brightman, M.W. Trans-glial channels in ventral nerve roots of crayfish. J. Comp. Neurol. 1976, 167, 1-26. [CrossRef] [PubMed]

63. Krill, J.L.; Dawson-Scully, K. Characterization of a novel stimulus-induced glial calcium wave in Drosophila larval peripheral segmental nerves and its role in PKG-modulated thermoprotection. J Neurogenet. 2021, 35, 221-235. [CrossRef] [PubMed]

64. Badre, N.H.; Cooper, R.L. Reduced calcium channel function in Drosophila disrupts associative learning in larva, and behavior in adults. Int. J. Zool. Res. 2008, 4, 152-164. [CrossRef]

65. O’Neil, A.S.; Kim, C.; Cooper, R.L. Learning and Memory retention in larval Drosophila. J. Entomol. 2020, 17, 36-47. [CrossRef] 